\title{
Diagnosis of Adrenoleukodystrophy Using Dried Blood Spots
}

\author{
Yukitoshi Ishikawa, Ryoji Minami and Tooru Nakao \\ Department of Pediatrics, Sapporo Medical College, \\ Sapporo 060
}

\begin{abstract}
Ishikawa, Y., Minami, R. and Nakao, T. Diagnosis of Adrenoleukodystrophy Using Dried Blood Spots. Tohoku J. exp. Med., 1985, 146 (1), 6972 - We have demonstrated the increased $\mathrm{C}_{26: 0} / \mathrm{C}_{22: 0}$ ratio in the fatty acids of sphingolipid fraction in dried blood spots on filter paper from the patient with adrenoleukodystrophy. The ratio of $\mathrm{C}_{26: 0} / \mathrm{C}_{22: 0}$ in the dried blood spots from the patient was 2.1-fold higher than those of the normal controls. This value was almost the same as the ratio in erythrocyte membrane sphingomyelin from the patient, because sphingolipid fraction in the dried blood spots consists of mainly the sphingomyelin from erythrocyte membranes. Blood samples are easy to obtain by mail and the method is useful in the diagnosis of the patient and screening for the families known to be at risk._ adrenoleukodystrophy; very long chain fatty acids; sphingolipid; dried blood spots
\end{abstract}

Adrenoleukodystrophy (ALD) is an X-linked disorder associated with progressive demyelination in the brain white matter and with the adrenal atrophy accompanying with characteristic inclusion (Schaumburg et al. 1972, 1974). Igarashi et al. (1976a, b) demonstrated the accumulation of very long chain fatty acids with more than 24 carbon chain lengths in the brain white matter and adrenal cortex, as components of cholesterol esters and gangliosides.

Diagnosis of the patients with ALD is biochemically possible by demonstrating the increased $\mathrm{C}_{26: 0} / \mathrm{C}_{22: 0}$ ratios in the fatty acids of the total lipids or sphingomyelin in various tissues such as plasma, erythrocyte membranes and cultured skin fibroblasts from the patients with ALD (Kawamura et al. 1978 ; Moser et al. 1981, 1983 ; Tsuji et al. 1981). These findings suggest that abnormal metabolism of very long chain fatty acids in ALD is systemic.

We measured very long chain fatty acids in sphingolipid fraction of the dried blood spots on filter paper by gas-liquid chromatography with a packed column for identification of the patients with ALD and their carriers. In this paper, we describe a pilot study on diagnosis for ALD and ALD-carrier using dried blood spots on filter paper.

Received October 1, 1984 ; accepted for publication December 12, 1984. 


\section{Materials and Methods}

Erythrocyte membranes were prepared from peripheral blood by hemolyzing with 1 volume of water and then by centrifuging at $1500 \mathrm{rpm}$. for $15 \mathrm{~min}$. Erythrocyte membranes obtained were extracted with 5 volumes of chroloform-methanol 1:2(V/V). After adding $1 \mathrm{ml}$ of $2 \mathrm{~N}$ methanolic $\mathrm{KOH}$, total lipids extracts from erythrocyte membranes were subjected to mild alkaline-methanolysis for $15 \mathrm{~min}$. at $37^{\circ} \mathrm{C}$. The mixtures were acidified with $\mathrm{HCl}$. Cholesterol esters, which were almost intact in mild alkaline condition, and the fatty acids released from triglyceride and glycerophospholipids were discarded by extracting three times with 1 volume of $n$-hexane. The methanolic phase containing intact sphingolipids was taken to dryness under nitrogen gas and then methanolyzed with $5 \%$ anhydrous methanolic $\mathrm{HCl}$ for $4 \mathrm{hr}$ at $90^{\circ} \mathrm{C}$. Fatty acids methyl esters from sphingolipids in erythrocyte membranes were analyzed by gas-liquid chromatography with $2 \% \mathrm{OV}-1$ column in a temperature programing of $170^{\circ} \mathrm{C}-285^{\circ} \mathrm{C} / \mathrm{min}$ at $3^{\circ} \mathrm{C} / \mathrm{min}$. All the peaks on the chromatogram were identified with gas chromatography-mass spectrometry (Hitachi RMU-6M, 3\% OV-1 column, $150^{\circ} \mathrm{C}-285^{\circ} \mathrm{C}, 5^{\circ} \mathrm{C} / \mathrm{min}$.)

Peripheral blood was spotted onto filter paper. The dried blood spots were cut in $\phi$ $10 \mathrm{~mm}$-disc and soaked with $0.5 \mathrm{ml}$ of water for $2 \mathrm{hr}$ at $37^{\circ} \mathrm{C}$. Then, the mixtures were stirred with $2 \mathrm{ml}$ of chroloform-methanol $1: 2(\mathrm{~V} / \mathrm{V})$ for $30 \mathrm{~min}$. at $37^{\circ} \mathrm{C}$. The mixtures were centrifuged at $1500 \mathrm{rpm}$. for $15 \mathrm{~min}$. and the disc was discarded. The extracts were subjected to mild alkaline-methanolysis by adding $0.5 \mathrm{ml}$ of $2 \mathrm{~N}$ methanolic $\mathrm{KOH}$. After extracting with $\mathrm{n}$-hexane, the methanolic phase containing intact sphingolipids was taken to dryness and methanolyzed. Fatty acid methyl esters from sphingolipids in the dried blood spots were analyzed with the condition described above. disc).

Analysis of the methyl esters was able to be employed three times in one spot ( $\phi 10 \mathrm{~mm}$

\section{RESUlts}

As shown in Fig. 1, $\mathrm{C}_{26: 0}$ peak of sphingolipids in the dried blood spots from the patient with ALD was significantly higher than that from normal control. Increased $\mathrm{C}_{26: 0} / \mathrm{C}_{22: 0}$ ratios of sphingolipid fraction in $\mathrm{ALD}$ and $\mathrm{ALD}$-mother (obligate heterozygote) were observed as compared to those in controls (Table 1). The ratio of $\mathrm{C}_{26: 0} / \mathrm{C}_{22: 0}$ in dried blood spots from $\mathrm{ALD}$ was 2.1-folds higher than

TABLE 1. $C_{26: 0} / C_{22: 0}$ ratios in sphingolipids of erythrocyte membranes and dried blood spots

\begin{tabular}{cccc}
\hline & \multicolumn{3}{c}{$\mathrm{C}_{26: 0} / \mathrm{C}_{22: 0}$ ratios } \\
\cline { 2 - 4 } & $\mathrm{ALD}$ & $\mathrm{ALD}-$ mother & Controls \\
\hline $\begin{array}{c}\text { Sphingolipids in erythrocyte } \\
\text { membranes }\end{array}$ & 0.2430 & 0.1406 & $\begin{array}{c}0.0841 \pm 0.0021 \dagger \\
(n=10)\end{array}$ \\
$\begin{array}{c}\text { Sphingomyelin in erythrocyte } \\
\text { membranes* }\end{array}$ & $0.26 \pm 0.04$ & & $0.10 \begin{array}{c} \pm 0.02 \\
(n=16)\end{array}$ \\
$\begin{array}{c}\text { Sphingolipids in dried blood } \\
\text { spots }\end{array}$ & 0.3617 & 0.2811 & $\begin{array}{c}0.1696 \pm 0.0056 \\
(n=10)\end{array}$ \\
\hline
\end{tabular}

* Values were reported by Tsuji et al. (1981).

$\dagger$ Means \pm s.D. 

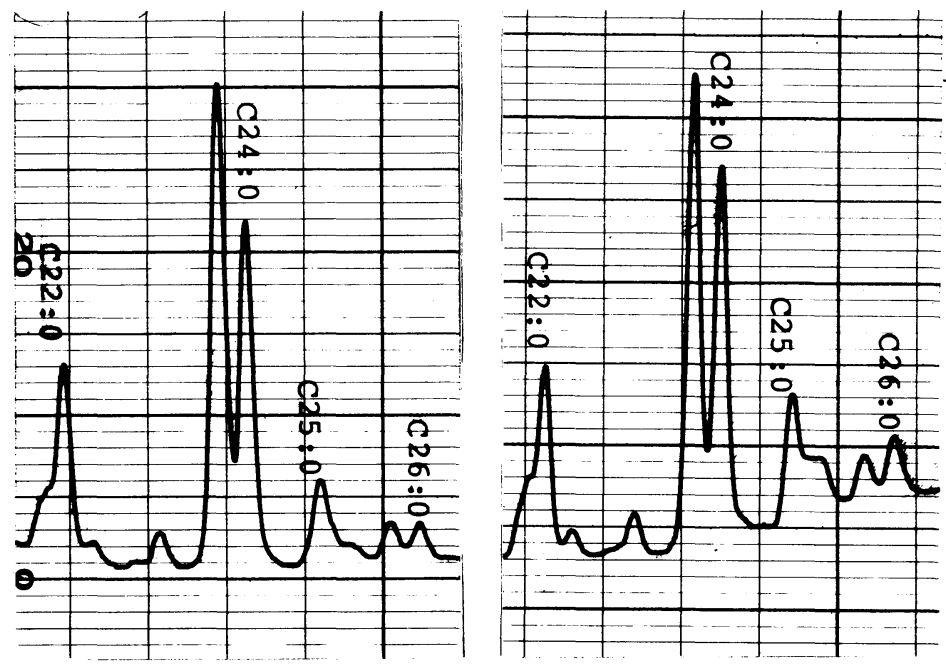

Fig. 1. Gas-chromatograms of fatty acid methyl esters of sphingolipids from dried blood spots. Left side: Normal control. Right side: ALD. For details see text.

that of controls. This value was almost the same as the ratio in erythrocyte membrane sphingomyelin from ALD (Tsuji et al. 1981), because sphingolipid fraction in dried blood spots consists of mainly the sphingomyelin from erythrocyte membranes.

\section{Discussion}

Singh et al. (1981) reported impared oxidation of very long chain fatty acids in cultured skin fibroblasts and adrenal cortex from the patient with ALD and suggested that abnormal metabolism of very long chain fatty acid was systemic.

As described in Results, the ratio of $\mathrm{C}_{26: 0} / \mathrm{C}_{22: 0}$ in dried blood spots was increased in the patient with ALD and diagnosis of ALD was possible using dried blood spots. Although we had assayed only one patient and one obligate heterozygote, the heterozygote for ALD was distinguishable from the patient with ALD and also from normal controls with regard to the $\mathrm{C}_{26: 0} / \mathrm{C}_{22: 0}$ ratio in sphingolipid fraction in the dried blood spots as well as in erythrocyte membranes.

At present, there is no reliable therapy for ALD, although therapeutic trials by restricting the dietary intake of very long chain fatty acids and plasmapheresis are attempted (Brown et al. 1982; Murphy et al. 1982). However, the identification of heterozygote for ALD is important for genetic counseling, because $\mathrm{ALD}$ is an $\mathrm{X}$-linked recessive trait and the prenatal diagnosis of ALD is now of value. Therefore, the demonstrations of increased $\mathrm{C}_{26: 0} / \mathrm{C}_{22: 0}$ rations of total lipids and sphingomyelin in cultured skin fibroblasts, plasma and erythrocyte membranes have been used to detect ALD and ALD-carrier. Although our method using dried blood spots is less expensive and easier to obtain many 
samples by mail as compared to those methods, the final evaluation should be made by the assay of plasma, erythrocyte membranes, and cultured skin fibroblasts, if the results of dried blood spots are clearly abnormal.

\section{Acknowledgments}

We thank Dr. A. Matsushima, Toyama National Sanatrium, Japan, for supplying samples.

\section{References}

1) Brown, III. F.R., Van Duyn, M.A., Moser, A.B., Schulman, J.D., Rizzo, W.B., Synder, R.D., Murphy, J.V., Kamoshita, S., Migeon, C.J. \& Moser, H.M. (1982) Adrenoleukodystrophy: Effects of dietary restriction of very long chain fatty acids and of administration of carnitine and clofibrate on clinical status and plasma fatty acids. Johns Hopk. med. J., 151, 164-172.

2) Igarashi, M., Schaumburg, H.H., Powers, J.M., Kishimoto, Y., Kolodny, E. \& Suzuki, K. (1976a) Fatty acid abnomality in adrenoleukodystrophy. J. Neurochem., 26, 851-860.

3) Igarashi, M., Belchis, D. \& Suzuki, K. (1976b) Brain gangliosides in adrenoleukodystrophy. J. Neurochem., 27, 327-328.

4) Kawamura, N., Moser, A.B., Moser, H.H., Ogino, T., Suzuki, K., Schaumburg, H., Milunsky, A., Murphy, J.V. \& Kishimoto, Y. (1978) High concentration of hexacosanoate in cultured skin fibroblast lipids from adrenoleukodystrophy patients. Biochem. biophys. Res. Commun., 82, 114-120.

5) Moser, H.W., Moser, A.B., Frayer, K.K., Chen, W., Schulman, J.D., O'Neill, B.P. \& Kishimoto, Y. (1981) Adrenoleukodystrophy: Increased plasma content of saturated very long chain fatty acids. Neurology (N.Y.), 31, 1241-1249.

6) Moser, H.W., Moser, A.B., Trojak, J.E. \& Supplee, S.W. (1983) Identification of female carriers of adrenoleukodystrophy. J. Pediatr., 103, 54-59.

7) Murphy, J.V., Marquardt, K.W. \& Van Duyn, M.A. (1982) Treatment of adrenoleukodystrophy by diet and plasmapheresis. Ann. Neurol., 12, 220.

8) Schaumburg, H.H., Richardson, E.P., Johnson, P.C., Cohen, R.B., Powers, J.M. \& Raine, C.S. (1972) Schilder's disease: Sex linked recessive transmission with specific adrenal change. Arch. Neurol., 27, 458-460.

9) Schaumburg, H.H., Powers, J.M., Raine, C.S., Suzuki, K. \& Richardson, E.P. (1974) Adrenoleukodustrophy (sex linked Schilder's disease): Ultrastructural demonstration of specific cytoplasmic inclusions in the central nervous system. Arch. Neurol., 31, 210-213.

10) Singh, I., Moser, H.W., Moser, A.B. \& Kishimoto, Y. (1981) Adrenoleukodystrophy : Impared oxidation of long chain fatty acids in cultured skin fibroblasts and adrenal cortex. Biochem. biophys. Res. Commun., 102, 1223-1229.

11) Tsuji, S., Suzuki, M., Ariga, T., Sekine, M., Kuriyama, M. \& Miyatake, T. (1981) Abnomality of long-chain fatty acids in erythrocyte membrane sphingomyelin from patients with adrenoleukodystrophy. J. Neurochem., 36, 1046-1049. 